Received 00th January 20xx, Accepted 00th January 20xx

DOI: $10.1039 / x 0 x \times 00000 x$

www.rsc.org/

\section{Surface functionalized 3D carbon fibers boosts the lithium storage behaviour of transition metal oxide nanowires via strong electronic interaction and tunable adsorption energy}

\author{
Lei Hu, ${ }^{\text {b+ }}$ Yingxia Gao, ${ }^{\text {at }}$ Tuzhi Xiong, ${ }^{\text {a }}$ David Adekoya, ${ }^{c}$ Weitao Qiu, ${ }^{\text {b }}$ Hao Yang, ${ }^{\mathrm{b}}$ M.-Sadeeq (Jie Tang)
} Balogun, ${ }^{*^{\mathrm{a}}}$ Shanqing Zhang, ${ }^{\mathrm{c}}$ Anlian Pan, ${ }^{\mathrm{a}}$ Yuping Li, ${ }^{\mathrm{a}}$ and Yexiang Tong ${ }^{\mathrm{b}}$
The Li-ion storage properties of transition metal oxide (TMOs) electrodes such as Li-ion intercalation-based electrodes are usually enhanced by hybridizing with 3D carbon scaffolds. However, understanding on the large variation of performance enhancement is rarely reported. As a proof of concept, intercalation reaction-based $\mathrm{TMOs}\left(\mathrm{V}_{2} \mathrm{O}_{5}\right.$ and $\left.\mathrm{TiO}_{2}\right)$ nanowires were hybridized with two types of 3D carbon scaffolds (namely pristine carbon fiber cloth, CFC and porous N-doped CFC, PNCFC). Theoretical calculation predicts that the PNCFC@TMOs hybrids displayed reasonable lower adsorption energy towards easier Liion intercalation than those of CFC@TMOs. Electrochemical properties further disclosed that PNCFC-based hybrids exhibit the best lithium storage performance. Furthermore, in situ Raman, XPS and charge redistribution studies not only decipher that strong electronic interaction exists between PNCFC and TMOs but also consistently affirm that such interaction is ascribed to the shift of the p-adsorption energy, facilitating rapid kinetics and leading to improved Li storage properties.

\section{Introduction}

$\mathrm{Li}$-ion intercalation reaction (LiIR)-based electrodes are one of the most promising electrode materials for lithium ion batteries (LIBs) because they offer the advantages of low volume expansion, stable solid electrolyte interface layer formation, little irreversible capacity loss and no electrolyte decomposition. ${ }^{1-5}$ The intercalation reaction of TMOs is shown as follows: ${ }^{6}$

\footnotetext{
a. College of Materials Science and Engineering, Hunan University, Changsha 410082, P.R.China.E-mail: balogun@hnu.edu.cn; liypli@hnu.edu.cn

MOE of the Key Laboratory of Bioinorganic and Synthetic Chemistry, The Key Lab of Low-carbon Chemistry \& Energy Conservation of Guangdong Province, KLGHEI of Environment and Energy Chemistry, School of Materials Science and Engineering, School of Chemistry, Sun Yat-sen University, Guangzhou 510275, P.R. China.E-mail: chedhx@mail.sysu.edu.cn

Centre for Clean Environment and Energy, Griffith School of Environment, Gold Coast Campus, Griffith University, QLD 4222, Australia.

These authors contribute equally.

Electronic Supplementary Information (ESI) available: [details of any supplementary information available should be included here]. See DOI: $10.1039 / x 0 \times x 00000 x$
}

$\mathrm{MO}+\mathrm{xLi}^{+}+\mathrm{xe}-\mathrm{Li}_{\mathrm{x}} \mathrm{MO}$

Transition metal oxides (TMOs) ${ }^{2,7-9}$ such as Ti oxides-based 10, 11 electrodes especially $\mathrm{TiO}_{2}$ and $\mathrm{V}$ oxides-based ${ }^{12-15}$ electrodes especially $\mathrm{V}_{2} \mathrm{O}_{5}$ usually exhibit such LilR mechanism. Meanwhile, these TMOs exhibit either poor electrochemical stability $\left(\mathrm{V}_{2} \mathrm{O}_{5}\right)$ or poor electrical conductivity $\left(\mathrm{V}_{2} \mathrm{O}_{5}\right.$ and $\left.\mathrm{TiO}_{2}\right)$ leading to loss in capacity and low rate capability, respectively. 16,17 In order to improve the dual dilemma of both $\mathrm{V}_{2} \mathrm{O}_{5}$ and $\mathrm{TiO}_{2}$, one of the common strategies employed is to design selfsupporting electrode materials by the direct growth of the active materials on 3D carbon scaffolds (e.g. carbon cloth, graphene, carbon nanotubes and so on). ${ }^{18-22}$ Such strategy could automatically prevent the intercalation of Li-ion into carbon scaffold (Li-ion usually intercalates in carbon-based material at a working potential below $1.0 \mathrm{~V}$ ) and make it easy to determine the capacity contribution of the active $\mathrm{V}_{2} \mathrm{O}_{5}$ and $\mathrm{TiO}_{2}$ materials. Previous literature has shown that the performance enhancement of the carbon scaffolds and TMOs hybrids can be attributed to the conductive 3D network and high surface area that allows rapid ion/electron transfer, enhanced conductivity and improved mechanical flexibility. ${ }^{19}$, ${ }^{23}$ However, despite the enhanced storage properties, ${ }^{24}$ the understanding on the intrinsic properties of the carbon scaffold and active electrodes is rarely reported. ${ }^{25,} 26$ In addition, less or no attention is given to the theoretical insight on the effect of such hybridization towards enhanced electrochemical activity. ${ }^{27}$

In this work, density functional theory (DFT) calculations were first studied to probe the intercalation of $\mathrm{Li}$-ion into $\mathrm{V}_{2} \mathrm{O}_{5}$ on pristine carbon fiber cloth (CFC) and porous $\mathrm{N}$-doped carbon fiber cloth (PNCFC). The PNCFC-based sample requires lower adsorption energy to complete intercalation process than the CFC counterparts. CFC was selected among the commonly reported carbon scaffolds owing to its good mechanical strength, stability, and wide application in energy storage researches. ${ }^{24,27-29}$ Electrochemical performance of PNCFC@V $\mathrm{V}_{2} \mathrm{O}_{5}$ presents superior Li storage properties over CFC@ $\mathrm{V}_{2} \mathrm{O}_{5}$. In situ Raman spectra and XPS consistently reveal that there exist strong electronic interaction between PNCFC and $\mathrm{V}_{2} \mathrm{O}_{5}$, which is valuable towards improving $\mathrm{Li}$ storage 
kinetics. Such strong electronic interaction allows the downshift of $\mathrm{p}$-band adsorption center that is favorable for enhancing the $\mathrm{Li}$ storage performance. More interestingly, based on the understanding of PNCFC@ $\mathrm{V}_{2} \mathrm{O}_{5}$, theoretical and experimental analyses further verifies that hybrid of $\mathrm{TiO}_{2}$ and PNCFC can also display similar phenomenon by modulating the $p$-orbital adsorption energy.

\section{Results}

\section{Theoretical Predictions}

Previous literature has reported that series of TMOs directly synthesized on 3D carbon scaffolds usually relate the enhanced performance to the 3D network. ${ }^{19,29,30}$ However, theoretical studies on the intercalation process of carbon compared to the active materials in their powdery forms are rarely studied. DFT calculations were first employed to investigate the optimum Gibb's free energy change $\left(\Delta \mathrm{G}_{\mathrm{H}^{*}}\right)$ required for $\mathrm{Li}$-ion diffusion through pristine $\mathrm{V}_{2} \mathrm{O}_{5}$ and $\mathrm{CFC} @ \mathrm{~V}_{2} \mathrm{O}_{5} \cdot{ }^{31,32}$ The diffusion barrier during diffusion process of Li-ion is very essential for understanding the electrode behaviour and the reasons for enhanced Li-ion storage performance. ${ }^{33,34}$ The optimized cluster structures of $\mathrm{V}_{2} \mathrm{O}_{5}$ and CFC@ $\mathrm{V}_{2} \mathrm{O}_{5}$ for the DFT calculations can be found in (Supporting information, Figure S1 and S2) and the free energy change diagrams of $\mathrm{V}_{2} \mathrm{O}_{5}$ and $\mathrm{CFC@} \mathrm{V}_{2} \mathrm{O}_{5}$ are shown in Figure $1 \mathrm{a}$ and $1 \mathrm{~b}$, respectively. The free energy change diagrams for these three electrodes are derived based on theoretical intercalation of Li-ions (i.e. lithiated state) into these electrodes. For example, Figure S3 shows the lithiated state of $\mathrm{V}_{2} \mathrm{O}_{5}$, while Figures $\mathrm{S} 4$ and $\mathrm{S} 7$ also show the lithiated state of both CFC@V $2 \mathrm{O}_{5}$ and PNCFC@ $\mathrm{V}_{2} \mathrm{O}_{5}$, respectively. Li-ion at the initial state (Figures S3-I and S4-I) accounts for $\Delta \mathrm{G}_{\mathrm{H}^{*}}$ of $0.0 \mathrm{eV}$ in both electrodes (Figure $1 \mathrm{a}-\mathrm{i}$ and $1 \mathrm{~b}$-iii). At the $\mathrm{V}_{2} \mathrm{O}_{5}$ surface, CFC@ $\mathrm{V}_{2} \mathrm{O}_{5}$ requires a lower diffusion barrier of $0.14 \mathrm{eV}$ (Figure S4-II and 1 b-ts-3), whereas the $\Delta \mathrm{G}_{\mathrm{H}^{*}}$ is much higher in $\mathrm{V}_{2} \mathrm{O}_{5}$ (0.19 eV, Figure S3-II and 1a-ts-1). Upon complete Li-ion intercalation into the lattice of the electrodes forming $\mathrm{Li}_{\mathrm{x}} \mathrm{V}_{2} \mathrm{O}_{5}$ (Figure S3-III), $\mathrm{V}_{2} \mathrm{O}_{5}$ will still have to overcome an energy barrier of $1.81 \mathrm{eV}$ (Figure 1a-ts-2). The lower diffusion barrier
$\left(\Delta \mathrm{G}_{\mathrm{H}^{*}}\right)$ of $0.95 \mathrm{eV}$ (Figures 1b-ts-4 and S4-III) for CFC@V $\mathrm{O}_{2}$ compared to that of pristine $\mathrm{V}_{2} \mathrm{O}_{5}$ indicates that rapid $\mathrm{Li}$-ion transportation and enhanced kinetics throughout the intercalation process and could result in superior performance of CFC@ $\mathrm{V}_{2} \mathrm{O}_{5}$ over pristine $\mathrm{V}_{2} \mathrm{O}_{5}$. Finally, the energy barrier of $\mathrm{V}_{2} \mathrm{O}_{5}$ and CFC@ $\mathrm{V}_{2} \mathrm{O}_{5}$ returned to $0.0 \mathrm{eV}$ (Figure 1a-ii and 1b-iv) after the entire intercalation process (Figure S3-IV and S4-IV), respectively.

Previously, we have shown that the surface of CFC can be functionalized with nitrogen $(\mathrm{N})$ atoms, high porosity, and better conductivity, which leads to high surface area and also serves as promising anode materials for LIBs. ${ }^{27,35}$ When the porous $\mathrm{N}$-doped functionalized CFC (denoted as PNCFC) was used as a current collector for the growth of conversion reaction-based TMOs such as $\mathrm{NiCO}_{2} \mathrm{O}_{4}$, experimental and theoretical analyses confirmed that there exists an electronic interaction between PNCFC and $\mathrm{NiCO}_{2} \mathrm{O}_{4}$, which is responsible for achieving high capacity of the hybrid. ${ }^{27}$ Additionally, $\mathrm{V}_{2} \mathrm{O}_{5}$ nanobelts ${ }^{36}$ and $\mathrm{V}_{2} \mathrm{O}_{5}$ nanosheets ${ }^{37}$ cathodes that were synthesized on graphene foam and carbon nanotubes (CNTs) displayed enhanced performance due to the 3D network and harmonious integration. ${ }^{36,37}$ Motivated by this concept, we utilized the PNCFC as a current collector for the direct synthesis of $\mathrm{V}_{2} \mathrm{O}_{5}$ nanowires (denoted as PNCFC@ $\mathrm{V}_{2} \mathrm{O}_{5} \mathrm{NWs}$ ) and compare its performance with that of CFC@ $\mathrm{V}_{2} \mathrm{O}_{5} \mathrm{NWs}$.

Theoretical predictions on PNCFC@ $\mathrm{V}_{2} \mathrm{O}_{5}$ hybrid was conducted based on the optimized structure model for PNCFC@ $V_{2} \mathrm{O}_{5}$ (Figure S5). The enlarged snapshot of covalent bonds between $C$ (a functional group of PNCFC) and $O$ (from $\mathrm{V}_{2} \mathrm{O}_{5}$ ), and between $\mathrm{O}$ (functional group of PNCFC) and $\mathrm{V}$ (from $\mathrm{V}_{2} \mathrm{O}_{5}$ ) are depicted in Figure $\mathrm{S} 6 \mathrm{a}$ and $\mathrm{S} 6 \mathrm{~b}$, respectively. This bonding shows that the functional groups revealed a close relationship between individual elements in the electrode. Compared to CFC@ $\mathrm{V}_{2} \mathrm{O}_{5}$, the optimum Gibb's free energy change $\left(\Delta \mathrm{G}_{\mathrm{H}^{*}}\right)$ required for Li-ion transportation in PNCFC@ $V_{2} \mathrm{O}_{5}$ is shown in Figure 1c. During Li-ion intercalation in PNCFC@ $\mathrm{V}_{2} \mathrm{O}_{5}$ (Figure S7), the $\Delta \mathrm{G}_{\mathrm{H}^{*}}$ at ts-5 and ts-6 are 0.06 and $0.35 \mathrm{eV}$, also indicating the complete lithiated state of $\mathrm{V}_{2} \mathrm{O}_{5}$, and significantly lower than those of CFC@ $\mathrm{V}_{2} \mathrm{O}_{5}$ and pristine $\mathrm{V}_{2} \mathrm{O}_{5}$.
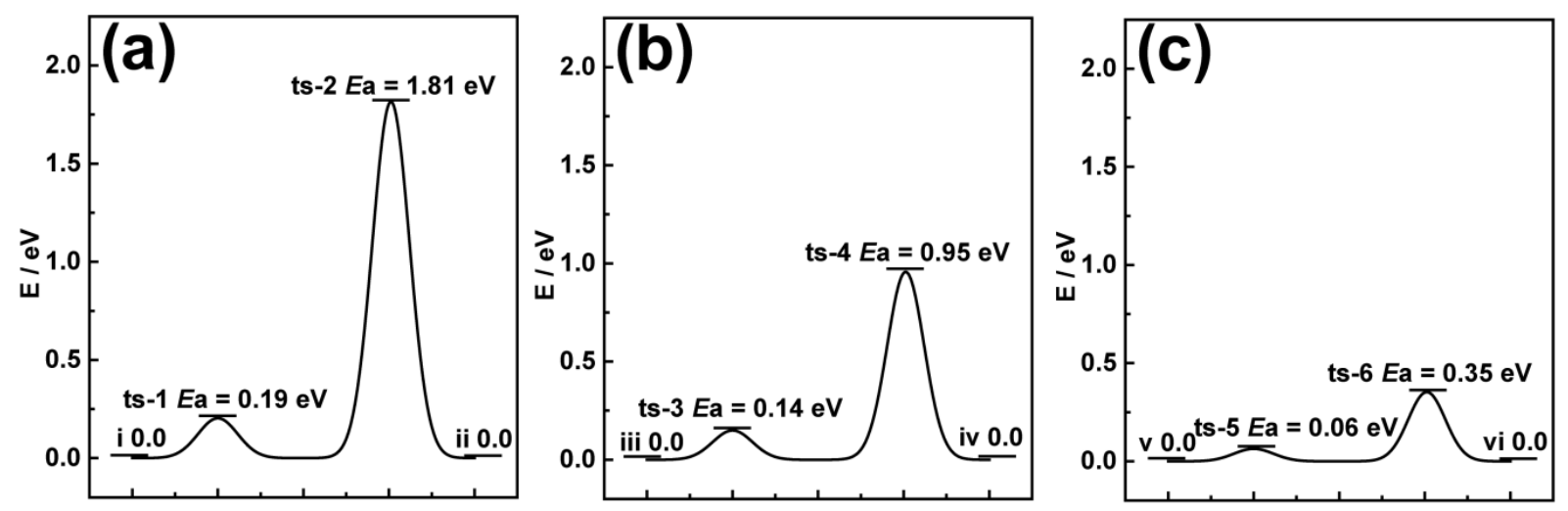

Figure 1. Calculated migration $\Delta \mathrm{G}_{\mathrm{H}^{*}}$ to Li-ion diffusion through (a) $\mathrm{V}_{2} \mathrm{O}_{5}$, (b) $C F C @ \mathrm{~V}_{2} \mathrm{O}_{5}$ and (c) PNCFC@ $\mathrm{V}_{2} \mathrm{O}_{5}$ from DFT calculations. 
The result further suggests that the support of functionalized 3D carbon scaffold with TMOs could not only hastens Li-ion diffusion pathway and enhances the kinetics but also lowers the adsorption energy towards achieving high performance LIBs.

\section{Synthesis and Morphological Characterization}

The scanning electron microscopy (SEM) images of the two current collectors, CFC and PNCFC (highly networked selfsupported current collectors) are shown in Figure S8a and S8b, respectively. The direct growth of $\mathrm{V}_{2} \mathrm{O}_{5} \mathrm{NWs}$ on the CFC and PNCFC self-supported materials was accomplished through hydrothermal and air-annealing treatments as previously reported. ${ }^{19}$ Schematic illustrations of $\mathrm{V}_{2} \mathrm{O}_{5}$ NWs fabrication process can be seen in Scheme S1 (details about synthetic method can be found in the experimental section). Firstly, a 24 $\mathrm{cm}^{2}$ piece of CFC was converted to PNCFC through hydrothermal reaction, thermal reduction and etching treatments (Scheme S1-I). ${ }^{38}$ SEM image clearly shows the porous and rough nature of the PNCFC surface as seen in Figure 2a. Transmission electron microscopy (TEM) analysis further reveals an exfoliated and porous surface on the PNCFC (Figure $2 a$ inset). For the CFC current collector, the approximate thickness of a single fiber is $9.6 \mu \mathrm{m}$ (Figure S9a), which reduces to $7.7 \mu \mathrm{m}$ after modification to PNCFC (Figure s9b).

Previous reports have demonstrated that lightweight substrates or current collectors with porous morphology could serve as favorable scaffolds for the growth of active materials, while reducing the weight of the entire cell ${ }^{24,36,39}$ and also contributed to the flexible properties of the electrodes. ${ }^{24,35,40,}$

${ }^{41}$ Thus, $\mathrm{VO}_{\mathrm{x}} \mathrm{NWs}$ (Figure S10) were synthesized on both CFC and PNCFC current collectors and annealed at $400{ }^{\circ} \mathrm{C}$ in the air to obtain CFC@V $\mathrm{O}_{5}$ (Scheme S1-II) and PNCFC@V ${ }_{2} \mathrm{O}_{5}$ NWs (Scheme S1-III), respectively.
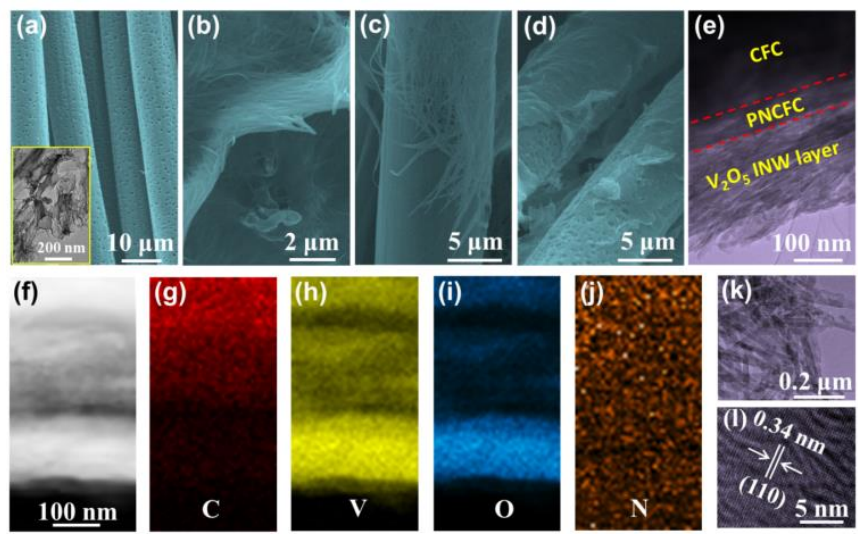

Figure 2. Morphological characterization. (a) SEM image of PNCFC showing the exfoliated porous surface. Inset is the corresponding TEM image. (b) SEM image of PNCFC@ $\mathrm{V}_{2} \mathrm{O}_{5}$ showing $\mathrm{V}_{2} \mathrm{O}_{5} \mathrm{NWs}$. (c) SEM image of CFC@ $\mathrm{V}_{2} \mathrm{O}_{5}$ showing the contact between CFC and $\mathrm{V}_{2} \mathrm{O}_{5}$. (d) SEM image of PNCFC@ $\mathrm{V}_{2} \mathrm{O}_{5}$ showing $\mathrm{V}_{2} \mathrm{O}_{5}$ NWs strictly adhered to the PNCFC surface. (e) TEM image of PNCFC@V $\mathrm{O}_{5} \mathrm{NWs}$ showing the core-double shell-like architecture. Elemental mapping of PNCFC@V $\mathrm{V}_{2} \mathrm{O}_{5}$ showing distribution of the elements from (f) HAADF, (g) C, (h) V, (i) $\mathrm{O}$, and (j) N. (k) TEM image of PNCFC@ $\mathrm{V}_{2} \mathrm{O}_{5} \mathrm{NWs}$ and (I) HRTEM image of PNCFC@ $\mathrm{V}_{2} \mathrm{O}_{5} \mathrm{NWs}$ displaying the lattice fringes.
According to the XRD pattern, both samples were characterized with $\mathrm{V}_{2} \mathrm{O}_{5}$ peaks (JCPDF Card \#65-0131) but there's no significant differences in the phases of the two samples (Figure S11). Both the SEM images for CFC@ $@ V_{2} \mathrm{O}_{5}$ and PNCFC@V $\mathrm{V}_{2} \mathrm{O}_{5}$ consist of interwoven NWs with diameters in the range of 300-800 nm (Figures S12 and 2b), respectively. Figure $2 \mathrm{c}$ clearly depicts that $\mathrm{V}_{2} \mathrm{O}_{5} \mathrm{NWs}$ were successfully coated on the smooth surface of CFC, while Figure $2 \mathrm{~d}$ affirms the growth of the NWs firmly adhered to the PNCFC current collector. Further information regarding the morphology of the adhesiveness of $\mathrm{V}_{2} \mathrm{O}_{5} \mathrm{NWS}$ and PNCFC current collector interface was accomplished by TEM analyses. Interestingly, the TEM images revealed three-layer (core-double shell) architecture of the sample (Figures $2 \mathrm{e}$ and S13), consisting of inner-core CFC layer, exfoliated carbon middle-shell layer and $\mathrm{V}_{2} \mathrm{O}_{5} \quad \mathrm{NWS}$ outer-shell layer. Energy dispersive X-ray spectroscopy (EDS) elemental mapping collected from Figure 2e with its corresponding HAADF (Figure 2f) displayed the distribution of $\mathrm{C}$ (Figure 2g-red), $\mathrm{V}$ (Figure $2 \mathrm{~h}$-yellow) and $\mathrm{O}$ (Figure 2i-blue) and $\mathrm{N}$ (Figure 2j-orange). Figure $2 \mathrm{~g}$ discloses that the intensity of $C$ (red colour) decreases from bulk (top side) to the surface (down side) and the presence of $\mathrm{V}$ and $\mathrm{O}$ at the outermost shell layer (Figure $2 \mathrm{~h}$ ) also confirms the formation of $\mathrm{V}_{2} \mathrm{O}_{5}$. The results obtained from the EDS analyses further certified that the $\mathrm{V}_{2} \mathrm{O}_{5} \mathrm{NWs}$ were successfully coated on a PNCFC current collector demonstrating a core-double shell design. Additionally, TEM image collected from PNCFC@ $\mathrm{V}_{2} \mathrm{O}_{5}$ NWs surface (Figure 2k) showed the single crystalline nature (Figure S14) and lattice spacing of $0.34 \mathrm{~nm}$ (Figure 2I), which corresponds to the (110) plane of $\mathrm{V}_{2} \mathrm{O}_{5}$ and also affirms the successful formation of $\mathrm{V}_{2} \mathrm{O}_{5}$ on PNCFC substrate.

\section{Electronic Structure Characterization}

The electronic structure and valence states of both CFC@ $\mathrm{V}_{2} \mathrm{O}_{5}$ and PNCFC@ $\mathrm{V}_{2} \mathrm{O}_{5}$ and more information on the relationship between $\mathrm{V}_{2} \mathrm{O}_{5}$ and the two types of current collectors were studied using X-ray photoelectron spectroscopy (XPS). The XPS survey spectra of CFC@ $V_{2} \mathrm{O}_{5}$ and PNCFC@ $@ V_{2} \mathrm{O}_{5}$ can be found in Figure S15a. C 1s of the PNCFC@ $\mathrm{V}_{2} \mathrm{O}_{5}$ exhibited a broad signal for the $\mathrm{C}-\mathrm{C}$ bond and additional broad peak compared to the CFC@V ${ }_{2} \mathrm{O}_{5}$ sample, which suggests some extent of modifications in the modified CFC coated samples (Figure 3a). ${ }^{35,42}$ Moreover, a peak at $\sim 400 \mathrm{eV}$ in the N 1s spectra of PNCFC@ $\mathrm{V}_{2} \mathrm{O}_{5}$ is totally absent in CFC@ $@ \mathrm{~V}_{2} \mathrm{O}_{5}$ sample (Figure 3b). This confirmed that that PNCFC@ $V_{2} \mathrm{O}_{5}$ sample is $\mathrm{N}$-doped. The $\mathrm{N}$-doping can be obtained during thermal reduction of $\mathrm{Ni}(\mathrm{OH})_{2} \cdot 0.75 \mathrm{H}_{2} \mathrm{O}$ precursor in $\mathrm{N}_{2}$ atmosphere. ${ }^{27,}{ }^{38}$ Compared to the $\mathrm{V} 2 \mathrm{p}$ XPS spectra of CFC@ $V_{2} \mathrm{O}_{5}$, the $\mathrm{V} 2 \mathrm{p}$ XPS spectra of both samples can be deconvoluted into two synthetic peaks $\left(516.3 \mathrm{eV}\right.$ for $\mathrm{V}^{4+}$ and $517.6 \mathrm{eV}$ for $\mathrm{V}^{5+}$ ) (Figure 3c-I and 3c-II) confirming that the $\mathrm{V}_{2} \mathrm{O}_{5}$ samples are mixed-valence in nature. ${ }^{43-47}$ Interestingly, the $\mathrm{V}^{5+} \mathrm{V} 2 \mathrm{p}$ XPS spectra of CFC@ $\mathrm{V}_{2} \mathrm{O}_{5}$, shifted to a lower binding energy (ca. $0.36 \mathrm{eV}$ ) in PNCFC-based sample, whereas, the $\mathrm{V}^{4+} \mathrm{V} 2 \mathrm{p}$ XPS spectra shifted to a lower binding energy (ca. $0.36 \mathrm{eV}$ ) for the PNCFC-based sample. 

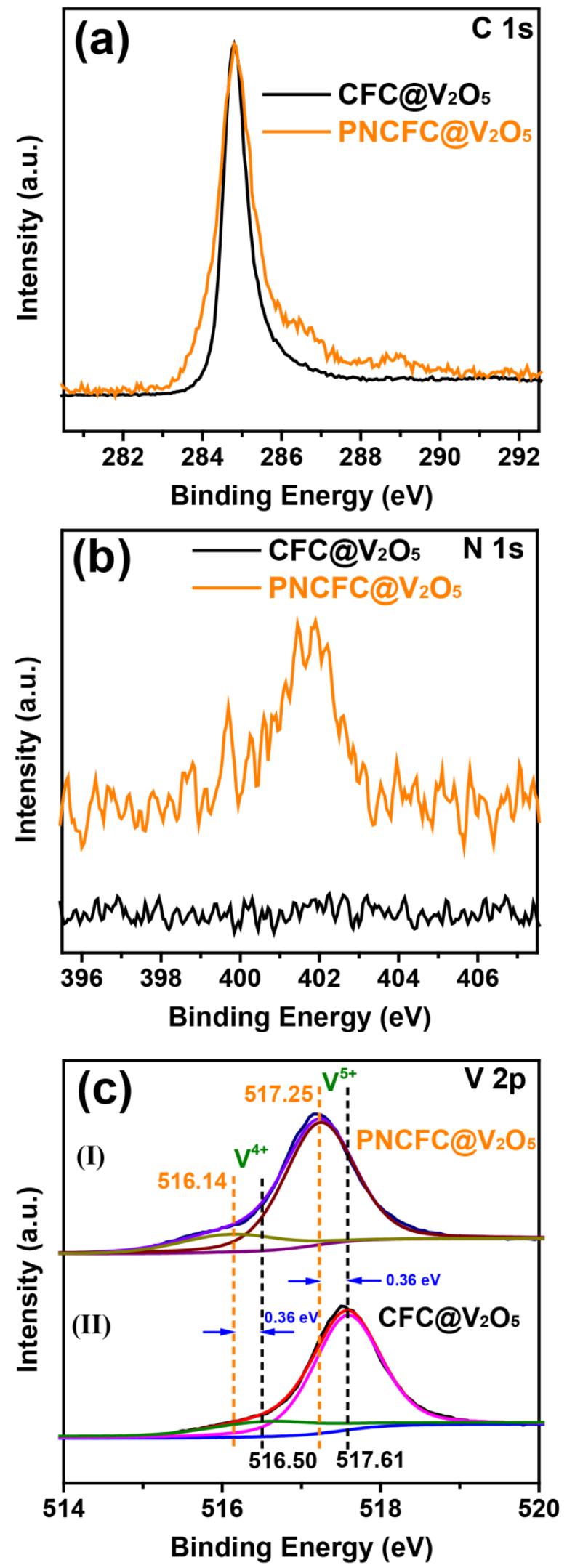

Figure 3. (a) $\mathrm{C} 1 \mathrm{~s}$, (b) $\mathrm{N} 1 \mathrm{~s}$ and (b) $\mathrm{V} 2 \mathrm{p}_{3 / 2}$ XPS spectra of CFC@ $\mathrm{V}_{2} \mathrm{O}_{5}$ and PNCFC@ $\mathrm{V}_{2} \mathrm{O}_{5}$.

This phenomenon indicates change in the electronic bonding environment state, justifies strong electronic interaction between PNCFC and $\mathrm{V}_{2} \mathrm{O}_{5}$ and suggests rapid transfer of electrons in PNCFC@ $\mathrm{V}_{2} \mathrm{O}_{5}$ sample. ${ }^{27,48}$ Moreover, the higher shift in the binding energy of the $\mathrm{V}^{4+}$ suggests stronger electronic interaction on the low valence state of PNCFC@ $\mathrm{V}_{2} \mathrm{O}_{5}$, which could be beneficial for enhancing the sample conductivity and kinetics. ${ }^{49}$ Additionally, the percentage ratio of the $\mathrm{V}^{4+} / \mathrm{V}^{5+}$ in the samples increased from $38 \%$ in CFC@V $\mathrm{O}_{5}$ to $47 \%$ in PNCFC@ $\mathrm{V}_{2} \mathrm{O}_{5}$ sample, meaning that a higher composition of $\mathrm{V}^{4+}$ improved the electronic interactions between $\mathrm{V}_{2} \mathrm{O}_{5}$ and PNCFC, which could also be an avenue for improving the electrochemical performance of PNCFC@ $\mathrm{V}_{2} \mathrm{O}_{5}{ }^{43}$

It has been previously proposed that the valence of vanadium oxides composites can be tailored, and could be a promising way to achieve high capacity, good conductivity and good cycling stability. ${ }^{44,45}$ For instance, self-doped of $\mathrm{V}^{4+}$ into $\mathrm{V}_{2} \mathrm{O}_{5}$ nanoflakes exhibit high structural stability, long-term and fast reversible Li storage capability resulting from the presence of $\mathrm{V}^{4+}$. ${ }^{43}$ Likewise $\mathrm{V}_{2} \mathrm{O}_{5}$ xerogels showed improved lithium storage performance benefiting from the multi-vanadium oxidation states and electrical conductivity. ${ }^{50}$ Thus, we proposed that the high composition of $\mathrm{V}^{4+}$ in PNCFC@ $\mathrm{V}_{2} \mathrm{O}_{5}$ arises from the electronic interaction between $\mathrm{V}_{2} \mathrm{O}_{5}$ and PNCFC, and this could eventually lead to improving the electrochemical performance of PNCFC@ $\mathrm{V}_{2} \mathrm{O}_{5}$ over CFC@ $\mathrm{V}_{2} \mathrm{O}_{5}$ sample. According to Figure S15b, the O 1s XPS spectra of PNCFC@V $\mathrm{O}_{2}$ is slightly different from that of CFC@ $\mathrm{V}_{2} \mathrm{O}_{5}$, also confirming that characteristic functional groups from PNCFC current collector and such functional groups are beneficial in improving electrode kinetic properties. ${ }^{27,51}$ Based on the Ex situ Raman spectroscopy analyses, the entire Raman peak below 1000 $\mathrm{cm}^{-1}$ corresponds with $\mathrm{V}_{2} \mathrm{O}_{5}$ Raman peaks reported in other literature (Figure S16a). ${ }^{52}$ More importantly, the Raman spectra presents a D:G peak intensity ratio of 1.48 for PNCFC@ $\mathrm{V}_{2} \mathrm{O}_{5}$ and also larger than that of the $\mathrm{CFC} @ \mathrm{~V}_{2} \mathrm{O}_{5}$ (1.32) (Figure S16b). In addition, the G-band of PNCFC@ $\mathrm{V}_{2} \mathrm{O}_{5}$ sample becomes broader further affirming modification of the treated CFC coated sample. This can be attributed to the porous exfoliated surface of the PNCFC substrate that consists of some surface disorder and presence of functional groups induced by etching, which is in agreement with the 01 s XPS spectra. ${ }^{35,53}$

\section{Li-Storage Properties}

Li storage behaviour and performance for both CFC@ $\mathrm{V}_{2} \mathrm{O}_{5}$ and PNCFC@ $V_{2} \mathrm{O}_{5}$ positive electrodes was studied in a coin cell. The $\mathrm{Li}$-ion insertion-deinsertion reactions in $\mathrm{V}_{2} \mathrm{O}_{5}$ can be seen from the 5th cyclic voltammetry (CV) curves for both electrodes (Figure S17) and the corresponding reaction mechanism can be seen as $\mathrm{V}_{2} \mathrm{O}_{5}+\mathrm{xLi}^{+}+\mathrm{xe}^{-} \rightleftharpoons \mathrm{Li}_{\mathrm{x}} \mathrm{V}_{2} \mathrm{O}_{5} .{ }^{36}$ Regular peaks of $\mathrm{V}_{2} \mathrm{O}_{5}$ can be found in both electrodes. ${ }^{54}$ PNCFC@ $V_{2} \mathrm{O}_{5}$ electrode shows stronger current density peaks than the CFC@ $\mathrm{V}_{2} \mathrm{O}_{5}$ electrode and also shift to higher voltage

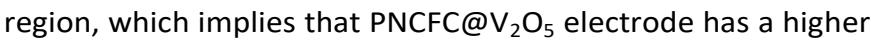
electrochemical reactivity and enhanced conductivity than the CFC@ $V_{2} \mathrm{O}_{5} .{ }^{36}$ Electrochemical impedance spectroscopy (EIS) analysis was carried out to have insight information on the kinetics of both CFC@ $\mathrm{V}_{2} \mathrm{O}_{5}$ and PNCFC@ $\mathrm{V}_{2} \mathrm{O}_{5}$ electrodes. 

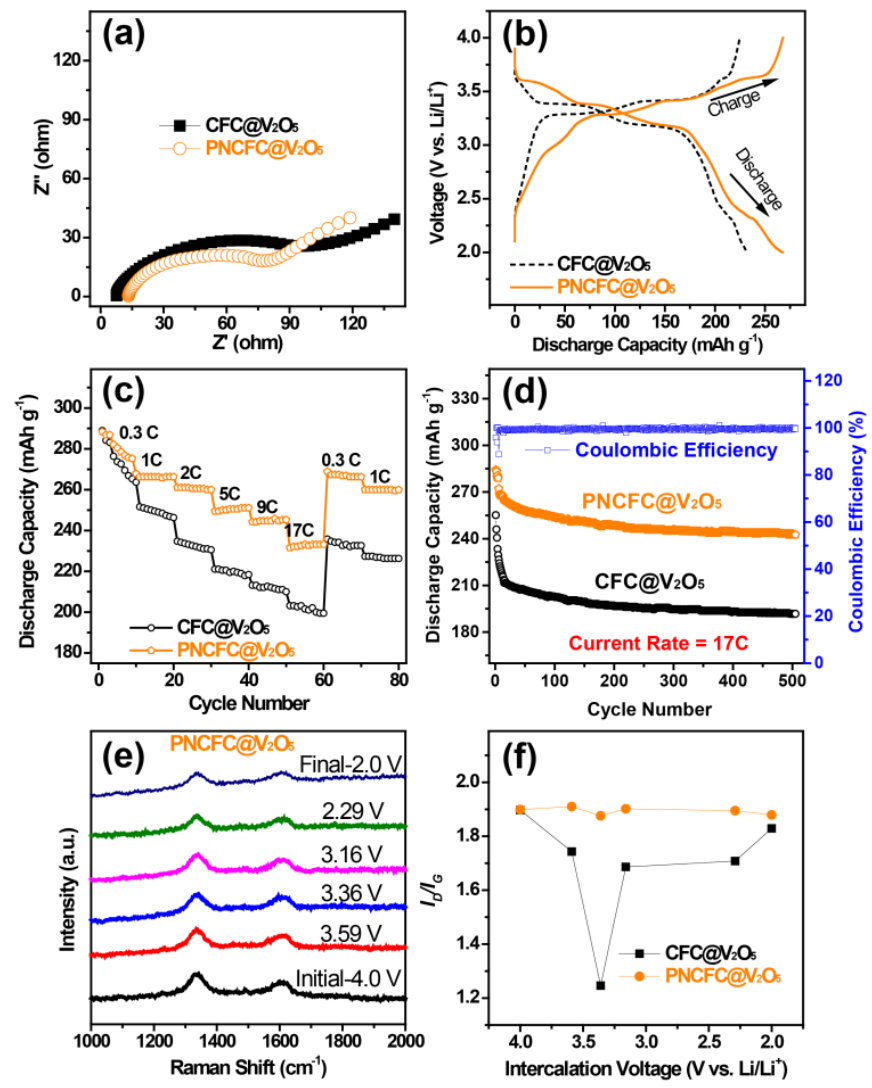

Figure 4. Li storage properties. (a) The Nyquist plots, (b) charge-discharge curves at a current density of $2.0 \mathrm{C}$, (c) rate capability and (d) cyclic stability at a current density of $2.0 \mathrm{C}$ of both CFC@ $\mathrm{V}_{2} \mathrm{O}_{5}$ and PNCFC@V $\mathrm{V}_{2} \mathrm{O}_{5}$. (e) In-situ Raman spectra of PNCFC@ $\mathrm{V}_{2} \mathrm{O}_{5}$ at different intercalated voltages. (f) The plot of the $\mathrm{I}_{\mathrm{D}} / \mathrm{I}_{\mathrm{G}}$ vs. intercalated voltages of $\mathrm{CFC} @ \mathrm{~V}_{2} \mathrm{O}_{5}$ and PNCFC@ $\mathrm{V}_{2} \mathrm{O}_{5}$

The Nyquist plot is characterized with a semi-circle and diffusion slope representing the charge transfer resistance $\left(R_{c t}\right)$ and Warburg impedance, respectively. ${ }^{19}$ The smaller the $R_{c t}$, the more the increase in the electron transfer rate of $\mathrm{V}_{2} \mathrm{O}_{5}$ in PNCFC@ $\mathrm{V}_{2} \mathrm{O}_{5}$ cell. As seen in Figure 4a, PNCFC@ $\mathrm{V}_{2} \mathrm{O}_{5}$ displays

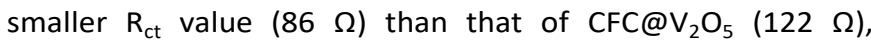
confirming the superior conductivity of PNCFC@ $\mathrm{V}_{2} \mathrm{O}_{5}$ electrode over $\mathrm{CFC} @ \mathrm{~V}_{2} \mathrm{O}_{5}$. As shown in Figure $4 \mathrm{~b}$, the discharge capacity of PNCFC@ $\mathrm{V}_{2} \mathrm{O}_{5}$ is $268 \mathrm{mAh} \mathrm{g}^{-1}$ after 10th electrochemical cycle, while that of CFC@ $\mathrm{V}_{2} \mathrm{O}_{5}$ is lower (233 $\mathrm{mAh} \mathrm{g}^{-1}$ ). It should be noted that energy efficiency (\%) is a vita parameter for the practical development of new electrode materials. The energy efficiency of a battery usually depends on the overpotentials of charging and discharging profiles and can be determined according to the formula below; ${ }^{55}$

Energy efficiency $=\frac{\text { Energy density }_{(\text {discharge })}}{\text { Energy density }{ }_{(\text {charge })}} \times 100 \%$

The energy density is determined by the area under the charge-discharge curves. According to Figure $4 b$, the energy efficiency of CFC@ $\mathrm{V}_{2} \mathrm{O}_{5}$ and PNCFC@ $@ \mathrm{~V}_{2} \mathrm{O}_{5}$ are approximately $95 \%$, which can still be maximized for practical interest. ${ }^{55}$ Figure $4 \mathrm{c}$ demonstrated the rate capability performance of

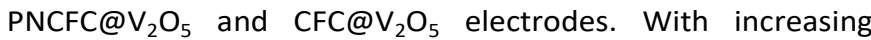
current density from $0.3 \mathrm{C}$ to $17 \mathrm{C}$, PNCFC@ $\mathrm{V}_{2} \mathrm{O}_{5}$ electrode continuously displayed superior performance over CFC@ $\mathrm{V}_{2} \mathrm{O}_{5}$ electrode. Unlike CFC@ $@ \mathrm{~V}_{2} \mathrm{O}_{5}$ electrode with capacity retention of 69\% at 17C, PNCFC@ $\mathrm{V}_{2} \mathrm{O}_{5}$ electrode performance delivered a reversible capacity of $233 \mathrm{mAh} \mathrm{g}^{-1}$ (81\% capacity retention) at current rate of $17 \mathrm{C}$. A clear difference can be observed with PNCFC@ $\mathrm{V}_{2} \mathrm{O}_{5}$ electrode retaining a specific capacity of 243 mAh $\mathrm{g}^{-1}$ (85\% capacity retention) with $100 \%$ coulombic efficiency, while its counterpart could only deliver $192 \mathrm{mAh} \mathrm{g}^{-1}$ ( $75 \%$ capacity retention) at the same testing current density of 17C for 500 cycles (Figure 4d). It can be observed that both electrodes show fast capacity decay in the first 20 cycles. Generally, the main problem of bulk $\mathrm{V}_{2} \mathrm{O}_{5}$ as electrode material for LIBs is its poor cyclic stability and rate capability. Thus, the fast capacity decay in the first 20 cycles for both the electrodes is a common phenomenon to $\mathrm{V}_{2} \mathrm{O}_{5}$. The SEM images of PNCFC@ $V_{2} \mathrm{O}_{5}$ electrode after stability test confirmed that the $\mathrm{V}_{2} \mathrm{O}_{5} \mathrm{NWs}$ were still strongly adhered to the surface of the PNCFC current collector (Figure S18). These results further verify the exemplary stability of the PNCFC@V ${ }_{2} \mathrm{O}_{5}$ electrode.

\section{In-situ Raman Analysis}

Additional analysis on the intercalation of Li-ion was done by in-situ Raman spectra for the two electrodes. Raman analysis is an effect strategy to study the effect of defect carbon and graphitic carbon in a sample. ${ }^{27}$ Detail process on the set-up can be found in Figure S19. The response of the current collectors $\mathrm{D}$ and $\mathrm{G}$ peaks towards Li-ion intercalation at different voltages can be effective for determining the impact of the different CFC current collectors. The Raman spectra collected for CFC@ $\mathrm{V}_{2} \mathrm{O}_{5}$ showed a non-uniform variation in its carbon $\mathrm{D}$ and $\mathrm{G}$ bands at different Li-ion voltages (Figure S19e), while that of PNCFC@ $\mathrm{V}_{2} \mathrm{O}_{5}$ showed nearly uniform variations in the $D$ and $G$ bands (Figure $4 \mathrm{e}$ ). The $I_{D} / I_{G}$ values of the electrodes are plotted against the intercalation at different voltages (Figure 4f) and the $I_{D} / I_{G}$ value of PNCFC@ $V_{2} \mathrm{O}_{5}$ cell is nearly the same at different Li-ion voltages, but varies and non-uniform for CFC@ $\mathrm{V}_{2} \mathrm{O}_{5}$. This result interprets that the $\mathrm{V}_{2} \mathrm{O}_{5}$ NWs are not strictly attached to the CFC surface leading to instability of CFC@ $@ V_{2} \mathrm{O}_{5}$ electrode. However, the $I_{D} / I_{G}$ values for PNCFC@ $\mathrm{V}_{2} \mathrm{O}_{5}$ indicate that there are strong interfacial interactions between the shell layer of the PNCFC and $\mathrm{V}_{2} \mathrm{O}_{5}$ NWs. These interactions are highly stable regardless of the voltage. Such strict adherence between the PNCFC and $\mathrm{V}_{2} \mathrm{O}_{5}$ NWs allows easy diffusion of $\mathrm{Li}$-ion and transportation of electrons into the entire electrode cavity. Both the theoretical analyses and experimental results are consistent and also account for the higher capacity retention and better stability of the PNCFC@ $\mathrm{V}_{2} \mathrm{O}_{5}$ electrode over the CFC@ $\mathrm{V}_{2} \mathrm{O}_{5}$.

\section{Discussion}

\section{Charge Redistribution and Adsorption Energy Capability}

The electronic interaction between $\mathrm{V}_{2} \mathrm{O}_{5}$ and PNCFC demonstrates a crucial role in enhancing the Li-storage properties of PNCFC@ $\mathrm{V}_{2} \mathrm{O}_{5}$. DFT calculations were further employed to investigate the charge distribution relationship between $\mathrm{V}_{2} \mathrm{O}_{5}$ and carbon scaffolds. The optimized model 
structures for CFC@ $\mathrm{V}_{2} \mathrm{O}_{5}$ and PNCFC@ $\mathrm{V}_{2} \mathrm{O}_{5}$ are displayed in Figures S2 and S5, respectively. Figure 5a distinctly displayed the natural bonding orbital (NBO) charge distribution in the optimized CFC@ $\mathrm{V}_{2} \mathrm{O}_{5}$ and PNCFC@ $\mathrm{V}_{2} \mathrm{O}_{5}$ obtained from DFT calculations.
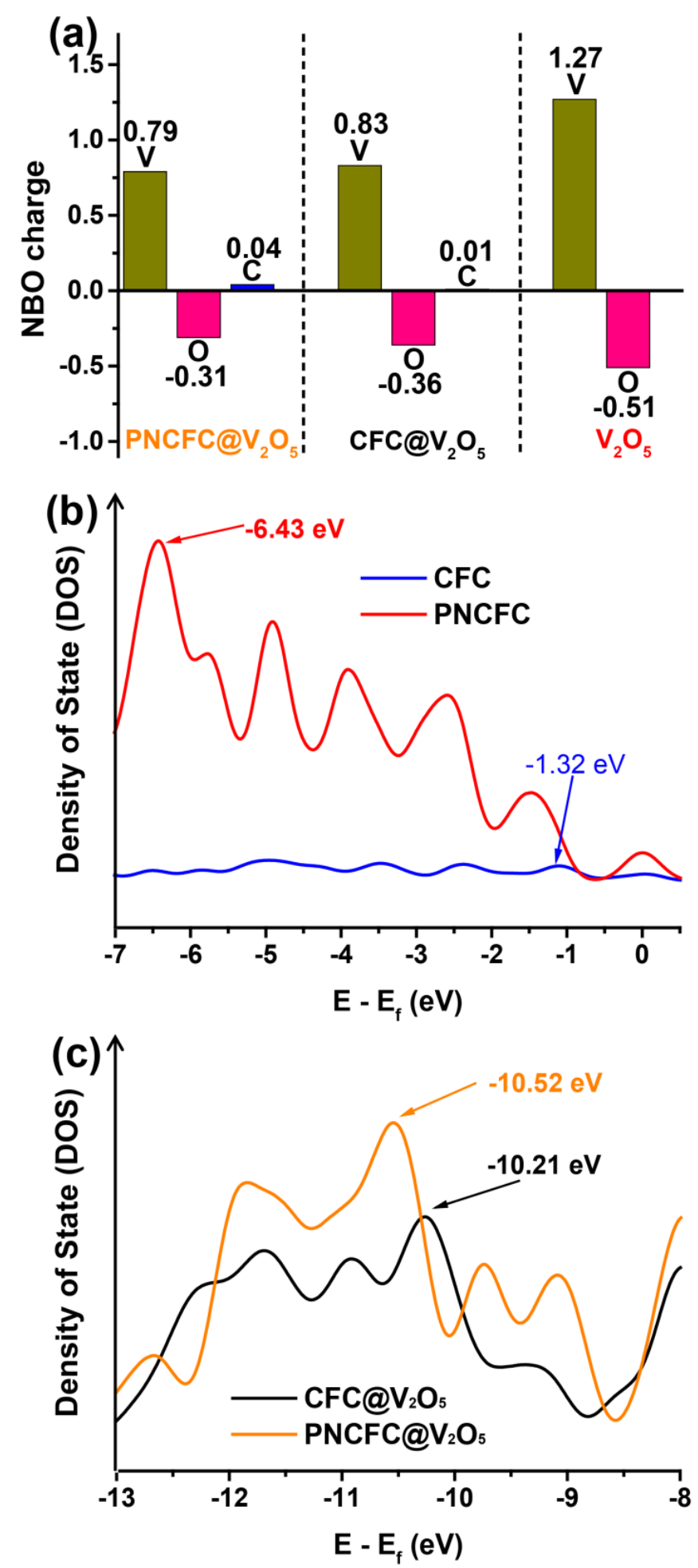

Figure 5. (a) NBO charge redistribution of $\mathrm{V}_{2} \mathrm{O}_{5}, C F C @ \mathrm{~V}_{2} \mathrm{O}_{5}$ and PNCFC@ $\mathrm{V}_{2} \mathrm{O}_{5}$. (b) DOS plots of CFC and PNCFC and their corresponding p-bands. (c) DOS plots of $\mathrm{CFC} @ \mathrm{~V}_{2} \mathrm{O}_{5}$ and PNCFC@ $\mathrm{V}_{2} \mathrm{O}_{5}$ and their corresponding p-bands.
The NBO charge distribution of pristine $\mathrm{V}_{2} \mathrm{O}_{5}$ was also introduced for comparison (optimized model structure in Figure S1). The charge distribution on PNCFC@ $\mathrm{V}_{2} \mathrm{O}_{5}$ shows that the positive charge on $\mathrm{V}$ is less electropositive, while the negative charge on $\mathrm{O}$ is less electronegative, in the order of PNCFC@V $\mathrm{V}_{2} \mathrm{O}_{5}>\mathrm{CFC} @ \mathrm{~V}_{2} \mathrm{O}_{5}>\mathrm{V}_{2} \mathrm{O}_{5}$. However, the positive charge on $\mathrm{C}$ of PNCFC@ $\mathrm{V}_{2} \mathrm{O}_{5}$ is more electropositive. These results indicate that the surface functionalization of PNCFC could change the electron density charges on the entire electrode, leading to excellent electronic interactions between PNCFC and $\mathrm{V}_{2} \mathrm{O}_{5}$ compared to that of CFC@ $\mathrm{V}_{2} \mathrm{O}_{5} \cdot{ }^{27}$ To obtain further understanding on the electronic interaction between the hybrids, the analysis of the density of states (DOS) related to the Fermi level $\left(E_{\mathrm{f}}\right)$ is studied and the corresponding $s, p, d, f$ and sum bands DOS are shown in Figure S20. Firstly, in all the samples, the p-band is more intense than those $s, d$ and $f$ bands and nearly the same with that of the sum-adsorption energy, indicating that the main Li-ion intercalation process is related to the $\mathrm{p}$-adsorption energy. The $\mathrm{p}$-adsorption energy center $\left(E_{p}\right)$ relative to $E_{f}$ of CFC is $-1.27 \mathrm{eV}$ and that of PNCFC is $-6.43 \mathrm{eV}$ (Figure $5 \mathrm{~b}$ ). The results indicate that $E_{\mathrm{p}}$ of PNCFC is farther away from the $E_{f}$, facilitating the energy band-gap to reduce and allowing $p$-band to undergo distinct shift in PNCFC than CFC. The hybridization of PNCFC with $\mathrm{V}_{2} \mathrm{O}_{5}$ could definitely require lower adsorption energy than that of CFCbased hybrids. Indeed, the $E_{\mathrm{p}}$ in PNCFC@V $\mathrm{O}_{5}$ also depicts a shift

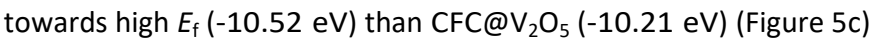
due to the increased bonding strength of PNCFC-based hybrid, that originates from the easy release and pulling of electrons from of PNCFC@ $V_{2} \mathrm{O}_{5}$. Hence, the energies of the charge density and valence band electrons will increase, enabling rapid electron transfer towards promoting fast Li-ion intercalation kinetics for enhanced Li-ion storage properties. Finally, both the NBO charge distribution and DOS results indicate changes in the bonding or electronic states and also in accordance with the $X P S$, finally affirming that there exist a stronger electronic interactions between PNCFC and $\mathrm{V}_{2} \mathrm{O}_{5}$ than pristine CFC and $\mathrm{V}_{2} \mathrm{O}_{5}$.

\section{$\mathrm{TiO}_{2}$-Based Anode: Electrochemical Properties and Mechanism Studies}

To obtain further understanding of the LilR-based mechanism, we also utilized $\mathrm{TiO}_{2}$ anode, which is also well known for its poor electrical conductivity leading to its slow kinetics and poor rate capability. Similar to $\mathrm{V}_{2} \mathrm{O}_{5}$, theoretical predictions on $\mathrm{TiO}_{2}$ hybridized with CFC and PNCFC were studied. DFT calculations conducted to determine the $\Delta \mathrm{G}_{\mathrm{H}^{*}}$ required for $\mathrm{Li}$ ion intercalation through $\mathrm{CFC@TiO} 2$ and PNCFC@TiO 2 . The optimized CFC@TiO 2 and PNCFC@TiO 2 cluster structures used for DFT calculations are presented in Figures S21 and S22, respectively. As Li-ion passes across the optimized CFC@ $\mathrm{TiO}_{2}$ structure (Figure S23), the $\Delta \mathrm{G}_{\mathrm{H}^{*}}$ required for the transportation of $\mathrm{Li}$-ion throughout CFC@ $@ \mathrm{TiO}_{2}$ is $1.11 \mathrm{eV}$ (Figure 6a). However, the maximum $\Delta \mathrm{G}_{\mathrm{H}^{*}}$ required is $0.51 \mathrm{eV}$ for PNCFC@TiO $\mathrm{T}_{2}$ to transport the $\mathrm{Li}$-ion through the entire PNCFC@TiO ${ }_{2}$ structure 

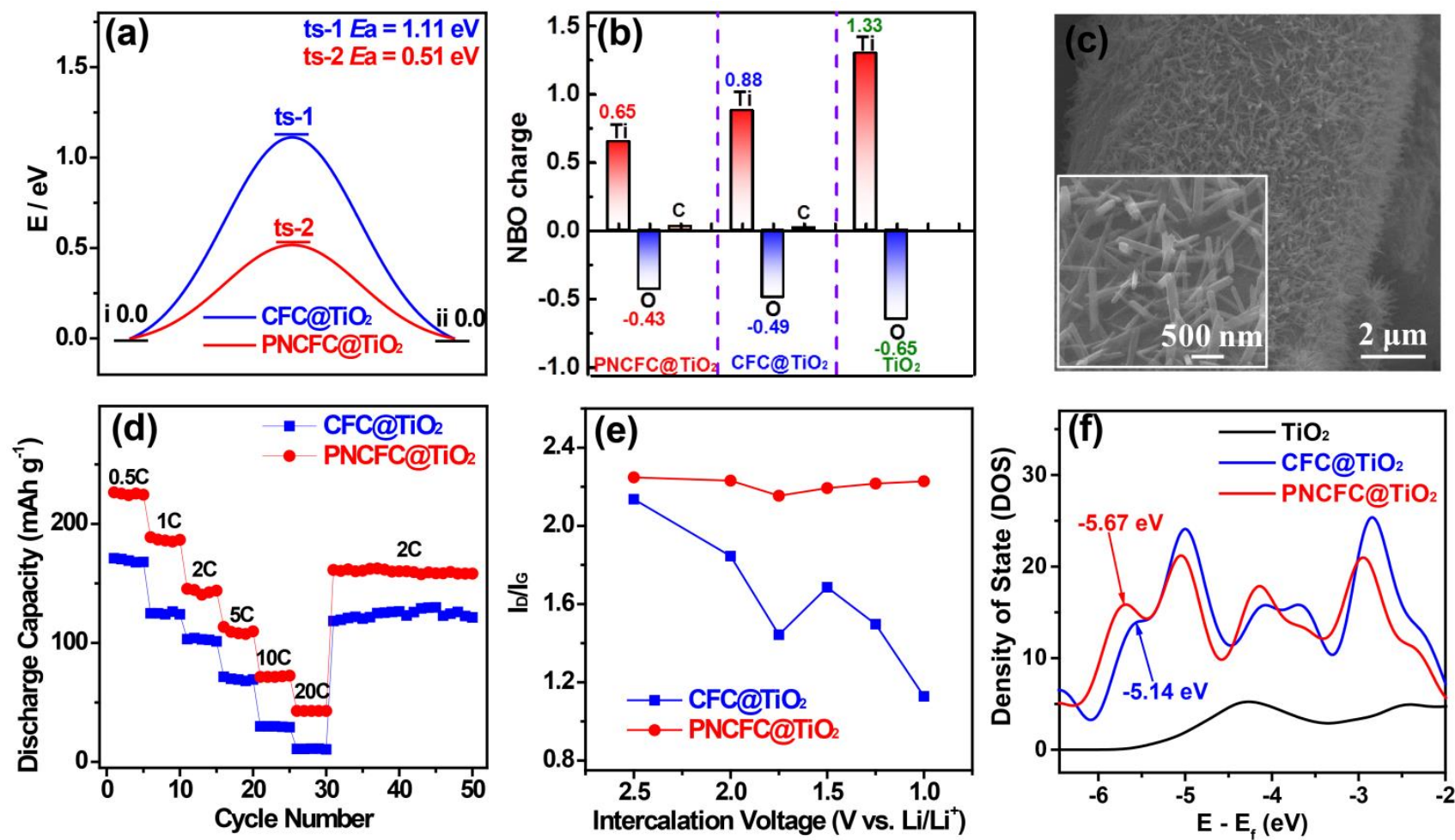

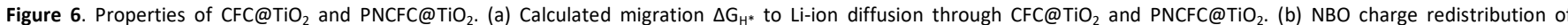
CFC@TiO ${ }_{2}$ and PNCFC@TiO ${ }_{2}$. (c) SEM images of PNCFC@ $\mathrm{TiO}_{2}$ NWs. (d) Rate performance and (e) Plot of the $I_{D} / I_{G}$ vs. intercalated voltages for CFC@TiO ${ }_{2}$ and PNCFC@TiO 2 . (f) DOS plots of $\mathrm{TiO}_{2}, \mathrm{CFC} @ \mathrm{TiO}_{2}$ and PNCFC@ $@ \mathrm{TiO}_{2}$ and their corresponding p-bands.

(Figure S24), which is also lower than that of CFC@TiO ${ }_{2}$. These results also correlate with that of $\mathrm{V}_{2} \mathrm{O}_{5}$ in Figure 1 . NBO charge distribution studies were also performed for the $\mathrm{TiO}_{2}$-based electrodes. Pristine $\mathrm{TiO}_{2}$ was also employed for comparison (optimized structure in Figure S25). The enlarged snapshot of covalent bonds between $\mathrm{O}$ (a functional group of ECC) and $\mathrm{Ti}$ (from $\mathrm{TiO}_{2}$ ) and an enlarged snapshot of covalent bonds between $\mathrm{C}$ (a functional group of ECC) and $\mathrm{O}$ (from $\mathrm{TiO}_{2}$ ) are shown in Figure S26.

According to the NBO charge redistribution in Figure $6 \mathrm{~b}$, compared to CFC@ $@ \mathrm{TiO}_{2}$ and pristine $\mathrm{TiO}_{2}$, the charge value on the positively charged $\mathrm{Ti}$ decreases, the positive charge on $\mathrm{C}$ increases and negatively charged O in PNCFC@TiO ${ }_{2}$, indicating that stronger electronic interactions between PNCFC and $\mathrm{TiO}_{2}$ of PNCFC@ $\mathrm{TiO}_{2}$. Hence, we hydrothermally coated Rutile-type $\mathrm{TiO}_{2}$ nanowires $\left(\mathrm{TiO}_{2} \mathrm{NWs}\right)$ (Figure S27) on CFC (CFC@TiO NWs) and PNCFC (PNCFC@TiO 2 NWs) according to our previous work (Figure 6c). ${ }^{11,16}$ Because $\mathrm{TiO}_{2}$ is known for its poor electrical conductivity, the rate capability performance was performed at different current densities and in the voltage range of 1.0-3.0 V (vs. Li/ $\mathrm{Li}^{+}$), where the PNCFC@TiO ${ }_{2}$ exhibited

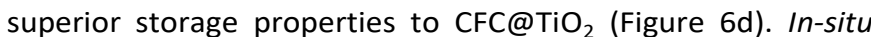
Raman spectra also shows that the PNCFC@TiO ${ }_{2}$ is more stable

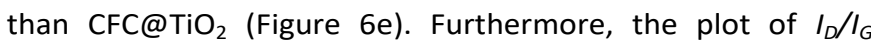
values against intercalation voltages collected from the whole results obtained for $\mathrm{TiO}_{2}$-based are in-line with those of $\mathrm{V}_{2} \mathrm{O}_{5}-$ based electrodes. Moreover, the $\mathrm{E}_{\mathrm{p}}$ of PNCFC@TiO 2 is $-5.67 \mathrm{eV}$,

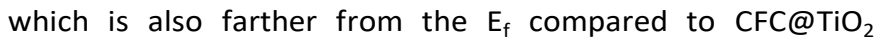
(Figure $6 f$ ), indicating a shift in the $E_{p}$, and could facilitate rapid

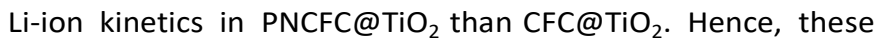
results did not clearly confirm the Li-ion storage properties of LilR-based TMO electrodes can be effectively modulated by tuning the p-adsorption energy level but also deciphered understanding on the large variation of performance enhancement in carbon scaffold-TMO electrode hybrids.

\section{Conclusions}

In summary, we systematically demonstrated the theoretical and experimental insights on the storage mechanism and large variation in the Li-ion storage performance of different carbon scaffolds as current collectors for LilR-based TMO electrodes. LilR-based electrodes, such as $\mathrm{V}_{2} \mathrm{O}_{5}$ and $\mathrm{TiO}_{2} \mathrm{NWs}$, were directly synthesized on two different carbon current collectors with different surface properties (CFC and PNCFC). DFT calculations revealed that Li-ion adsorption occurred at lower adsorption energy $\left(\Delta \mathrm{GH}^{*}\right)$ level of 7.75 and $4.64 \mathrm{eV}$ for PNCFC@ $V_{2} \mathrm{O}_{5}$ and PNCFC@TiO ${ }_{2}$, respectively compared to those of CFC@ $@ \mathrm{~V}_{2} \mathrm{O}_{5}(18.21 \mathrm{eV}), \mathrm{V} 2 \mathrm{O} 5$ (29.04 eV), CFC@TiO $(6.67 \mathrm{eV})$ and $\mathrm{TiO}_{2}(11.34 \mathrm{eV})$. Electrochemical performance confirmed that the $\mathrm{V}_{2} \mathrm{O}_{5}$ and $\mathrm{TiO}_{2} \mathrm{NWs}$ coated on PNCFC exhibited better Li-storage activity than those hybridized on CFC. Additionally, in-situ Raman spectra analysis revealed PNCFC could serve as a better scaffold for the electrodes in enhancing the cyclic stability and rate capability of the PNCFCbased electrodes than CFC. XPS, NBO charge distribution and DOS analyses showed that the PNCFC-based electrodes are attributed to stronger electronic interaction between the 
PNCFC and TMOs due to the shift of p-adsorption energy level. This work deciphers insight into the Li-storage mechanism and performance modulation of carbon-based current collectors and LilR-based electrodes.

\section{Conflicts of interest}

"There are no conflicts to declare".

\section{Acknowledgements}

This work was supported by the National Natural Science Foundation of China (21875292 and 51525202), National Key Research and Development Program of China (2016YFA0202604), the Fundamental Research Funds for the Central Universities (17/gjc36) and Science Starting Foundation of Hunan University (531118010182).

\section{References}

1. T. Zhou, Y. Zheng, H. Gao, S. Min, S. Li, H. K. Liu and Z. Guo, Adv. Sci., 2015, 2, 1500027.

2. V. Aravindan, Y.-S. Lee and S. Madhavi, Adv. Energy Mater., 2015, 5, 1402225.

3. S. Cao, Z. Xue, C. Yang, J. Qin, L. Zhang, P. Yu, S. Wang, Y. Zhao, X. Zhang and R. Liu, Nano Energy, 2018, 50, 25-34.

4. S. Joshi, Q. Wang, A. Puntambekar and V. Chakrapani, ACS Energy Lett., 2017, 2, 1257-1262.

5. Z. Yao, X. Xia, D. Xie, Y. Wang, C.-a. Zhou, S. Liu, S. Deng, X. Wang and J. Tu, Adv. Funct. Mater., 2018, 28, 1802756.

6. X. Xia, D. Chao, C. F. Ng, J. Lin, Z. Fan, H. Zhang, Z. X. Shen and H. J. Fan, Mater. Horiz., 2015, 2, 237-244.

7. X. Xia, S. Deng, S. Feng, J. Wu and J. Tu, J. Mater. Chem. A, 2017, 5, 21134-21139.

8. F. Wang, X. Wang, Z. Chang, Y. Zhu, L. Fu, X. Liu and Y. Wu, Nanoscale Horiz., 2016, 1, 272-289.

9. C. Wang, L. Wu, H. Wang, W. Zuo, Y. Li and J. Liu, Adv. Funct Mater., 2015, 25, 3524-3533.

10. V. Augustyn, E. R. White, J. Ko, G. Grüner, B. C. Regan and B. Dunn, Mater. Horiz., 2014, 1, 219-223.

11. M.-S. Balogun, M. Yu, C. Li, T. Zhai, Y. Liu, X. Lu and Y. Tong, J. Mater. Chem. A, 2014, 2, 10825-10829.

12. Y. Dai, Q. Li, S. Tan, Q. Wei, Y. Pan, X. Tian, K. Zhao, X. Xu, Q. An, L. Mai and Q. Zhang, Nano Energy, 2017, 40, 73-81.

13. Y. Yue and H. Liang, Adv. Energy Mater., 2017, 7, 1602545.

14. J. Yao, Y. Li, R. C. Massé, E. Uchaker and G. Cao, Energy Stor. Mater., 2018, 11, 205-259.

15. S. Wang, K. A. Owusu, L. Mai, Y. Ke, Y. Zhou, P. Hu, S. Magdassi and Y. Long, Appl. Energ., 2018, 211, 200-217.

16. M.-S. Balogun, C. Li, Y. Zeng, M. Yu, Q. Wu, M. Wu, X. Lu and Y. Tong, J. Power Sources, 2014, 272, 946-953.

17. B. Long, M.-S. Balogun, L. Luo, Y. Luo, W. Qiu, S. Song, L. Zhang and Y. Tong, Small, 2017, 13, 1702081.

18. L. Shen, B. Ding, P. Nie, G. Cao and X. Zhang, Adv. Energy Mater., 2013, 3, 1484-1489.

19. M.-S. Balogun, Y. Luo, F. Lyu, F. Wang, H. Yang, H. Li, C. Liang, M. Huang, Y. Huang and Y. Tong, ACS Appl. Mater. Interfaces, 2016, 8, 9733-9744.
20. Y. Shi, L. Wen, G. Zhou, J. Chen, S. Pei, K. Huang, H. M. Cheng and F. Li, 2d Mater., 2015, 2, 024004

21. S. Yoon, S. Lee, S. Kim, K.-W. Park, D. Cho and Y. Jeong, J. Power Sources, 2015, 279, 495-501.

22. G. Qian, X. Liao, Y. Zhu, F. Pan, X. Chen and Y. Yang, ACS Energy Lett., 2019, 4, 690-701.

23. X. Min, B. Sun, S. Chen, M. Fang, X. Wu, Y. g. Liu, A. Abdelkader, Z. Huang, T. Liu, K. Xi and R. Vasant Kumar, Energy Stor. Mater., 2019, 16, 597-606.

24. S. Liu, Z. Wang, C. Yu, H. B. Wu, G. Wang, Q. Dong, J. Qiu and A. Eychmüller, Adv. Mater., 2013, 25, 3462-3467.

25. Y. Deng, S. Dong, Z. Li, H. Jiang, X. Zhang and X. Ji, Small Methods, 2018, 2, 1700332.

26. X. Huang, G. Diao, S. Li, M.-S. Balogun, N. Li, Y. Huang, Z.-Q. Liu and Y. Tong, RSC Adv., 2018, 8, 17056-17059.

27. M.-S. Balogun, H. Yang, Y. Luo, W. Qiu, Y. Huang, Z.-Q. Liu and Y. Tong, Energy Environ. Sci., 2018, 11, 1859-1869.

28. H.-p. Feng, L. Tang, G.-m. Zeng, J. Tang, Y.-c. Deng, M. Yan, Y.n. Liu, Y.-y. Zhou, X.-y. Ren and S. Chen, J. Mater. Chem. A, 2018, 6, 7310-7337.

29. M.-S. Balogun, M. Yu, Y. Huang, C. Li, P. Fang, Y. Liu, X. Lu and Y. Tong, Nano Energy, 2015, 11, 348-355

30. G. X. Pan, X. H. Xia, F. Cao, J. Chen and Y. J. Zhang, Electrochim. Acta, 2014, 149, 349-354.

31. Y. Chu, L. Guo, B. Xi, Z. Feng, F. Wu, Y. Lin, J. Liu, D. Sun, J. Feng, Y. Qian and S. Xiong, Adv. Mater., 2018, 30, 1704244.

32. Y. Zheng, T. Zhou, X. Zhao, W. K. Pang, H. Gao, S. Li, Z. Zhou, H. Liu and Z. Guo, Adv. Mater., 2017, 29, 1700396.

33. J. Hu, C. Ouyang, S. A. Yang and H. Y. Yang, Nanoscale Horiz., 2019, 4, 457-463.

34. S. Ullah, P. A. Denis and F. Sato, Appl. Mater. Today, 2017, 9, 333-340.

35. M.-S. Balogun, W. Qiu, F. Lyu, Y. Luo, H. Meng, J. Li, W. Mai, L. Mai and Y. Tong, Nano Energy, 2016, 26, 446-455.

36. D. Chao, X. Xia, J. Liu, Z. Fan, C. F. Ng, J. Lin, H. Zhang, Z. X. Shen and H. J. Fan, Adv. Mater., 2014, 26, 5794-5800.

37. D. Kong, X. Li, Y. Zhang, X. Hai, B. Wang, X. Qiu, Q. Song, Q.-H. Yang and L. Zhi, Energy Environ. Sci., 2016, 9, 906-911.

38. M.-S. Balogun, W. Qiu, H. Yang, W. Fan, Y. Huang, P. Fang, G. Li, H. Ji and Y. Tong, Energy Environ. Sci., 2016, 9, 3411-3416.

39. X. Fang, M. Ge, J. Rong and C. Zhou, ACS Nano, 2014, 8, 48764882.

40. K. Wang, S. Luo, Y. Wu, X. He, F. Zhao, J. Wang, K. Jiang and S. Fan, Adv. Funct. Mater., 2013, 23, 846-853.

41. D. Chao, C. Zhu, X. Xia, J. Liu, X. Zhang, J. Wang, P. Liang, J. Lin, H. Zhang and Z. X. Shen, Nano Lett., 2014, 15, 565-573.

42. W. Wang, W. Liu, Y. Zeng, Y. Han, M. Yu, X. Lu and Y. Tong, Adv. Mater., 2015, 27, 3572-3578.

43. H. Song, C. Liu, C. Zhang and G. Cao, Nano Energy, 2016, 22, 1 10.

44. S. D. Perera, B. Patel, N. Nijem, K. Roodenko, O. Seitz, J. P. Ferraris, Y. J. Chabal and K. J. Balkus, Adv. Energy Mater., 2011 1, 936-945.

45. Y. Song, T.-Y. Liu, B. Yao, T.-Y. Kou, D.-Y. Feng, X.-X. Liu and Y. Li, Small, 2017, 13, 1700067

46. Y. Huang, Y. Lu, Y. Lin, Y. Mao, G. Ouyang, H. Liu, S. Zhang and Y. Tong, J. Mater. Chem. A, 2018, 6, 24740-24747.

47. Y. Huang, L. Hu, R. Liu, Y. Hu, T. Xiong, W. Qiu, M. S. Balogun, A. Pan and Y. Tong, Appl. Catal. B-environ, 2019, 251, 181-194.

48. Y. Sun, K. Xu, Z. Wei, H. Li, T. Zhang, X. Li, W. Cai, J. Ma, H. J. Fan and Y. Li, Adv. Mater., 2018, 30, 1802121. 
49. G. Diao, M.-S. Balogun, S.-Y. Tong, X. Guo, X. Huang, Y. Mao and Y. Tong, J. Mater. Chem. A, 2018, 6, 15274-15283.

50. D. Liu, Y. Liu, A. Pan, K. P. Nagle, G. T. Seidler, Y.-H. Jeong and G. Cao, J. Phys. Chem. C, 2011, 115, 4959-4965.

51. K. Ye, K. Li, Y. Lu, Z. Guo, N. Ni, H. Liu, Y. Huang, H. Ji and P. Wang, TrAC Trends in Anal. Chem., 2019, 116, 102-108.

52. M. Gotić, S. Popović, M. Ivanda and S. Musić, Mater. Lett., 2003, 57, 3186-3192.

53. G. Wang, H. Wang, X. Lu, Y. Ling, M. Yu, T. Zhai, Y. Tong and Y. Li, Adv. Mater., 2014, 26, 2676-2682.

54. P. Zhang, L. Zhao, Q. An, Q. Wei, L. Zhou, X. Wei, J. Sheng and L. Mai, Small, 2016, 12, 1082-1090.

55. A. Eftekhari, Sustainable Energy Fuels, 2017, 1, 2053-2060. 